\title{
Rapor
}

\section{Halk Sağlığı disiplininin ahlaki değerleri ve ilkeleri}

\author{
M. Murat Civanera
}

a Doç.. Dr., Uludağ Üniversitesi Tıp Fakültesi, Tıp Tarihi ve Etik Anabilim Dalı, Bursa

\section{Özet}

Halk Sağlığı disiplininin birey ve toplumun sağlığını korumayı ve geliştirmeyi amaçladığı, genellikle gerekçesini sorgulamadan kabul edilir. Bununla birlikte, bu kabulün gerekçesini, böyle bir amacın neden değerli olduğunu ifade etmek, Halk Sağlı̆̆ uygulamalarına yön vermek ve var olan uygulamaların amaçla ne kadar örtüştüguünü değerlendirmek açısından önemlidir. Bu yazıda, disiplinin var oluş amacının dayandığı değer ve ilkeler temellendirilmekte, ayrıca bu değer ve ilkelerden kalkarak meslek ahlakı kuralları tanımlanması için çağrıda bulunulmaktadır.

Anahtar Kelimeler: Halk sağlığı, etik, biyoetik, halk sağlı̆̆ı etiği, meslek ahlakı kodları

\section{Moral values and principles of Public Health as a discipline}

\begin{abstract}
It is widely accepted, without questioning its justification, that Public Health as a discipline aims to protect and promote individuals' and society's health. However, grounding its justification and expressing the reasons for making that aim a valuable one is vital for guiding and implementing public health interventions and evaluating their concordance with that aim. In this article, the ethical values and principles of Public Health are justified, and a call is made for developing a professional code of ethics.
\end{abstract}

Key Words: Public health, ethics, bioethics, public health ethics, professional code of ethics.

Sorumlu Yazar: M. Murat Civaner, Uludağ Üniversitesi Tıp Fakültesi, Tıp Tarihi ve Etik Anabilim Dalı, Bursa; E-mail: mcivaner@gmail.com Tel: 2242954272 


\section{Giriş}

Halk Sağlığı disiplininin, temel olarak, kendi içlerinde birer ada olmaktan çok birbirleriyle etkileşim içinde olan bireylerin sağlı̆ını bir toplum olarak korumayı ve geliştirmeyi amaçladığı kabul edilir. Bununla birlikte, 'neden böyle bir amacı olduğu' sorusu sıklıkla gündeme gelmez; büyük olasılıkla, sağlık, adı üzerinde, sağ olmanın, yaşamanın önkoşulu olduğu için, ayrıca 'Halk Sağlığı' isimli bir disiplinin toplum sağlığını geliștirmeyi hedeflemesi doğal kabul edildiği için böyle bir sorunun yanıtının herkesçe kabul edildiği örtük biçimde varsayılır. Oysa bu soruya verilen yanıtın gerekçesi göründüğü kadar doğal / açık olmayabilir: Bireylerin ve toplumun sağlığını neden koruyup geliştirmek isteriz? Bu kendi içinde ahlaki bir yükümlülük müdür, yoksa sadece araçsal bir hedef midir? Halk Sağlığı uygulamaları, örneğin ertesi günün iş gücünü güvence altına alabilmek için mi önemlidir? Yoksa "gürbüz nesiller" yetiștirmek, "bedenen sağlıklı millet" olmak, nüfusu artırmak, orduyu güçlendirmek ya da ülkenin spor başarılarını artırmak için mi önem verilmelidir? Uyuşturucu bağımlılığı ile neden mücadele edilmelidir? Bilimsel bilgi ve teknolojinin örneğin 19. yüzyıla göre önemli derecede artması ve insanlığa büyük olanaklar sunması, tüm bireylere en azından sağlıklı yaşamın temel koşullarının sağlanması, temiz su, hava, gıda ve barınma koşullarının sunulması için çalışmak gibi bir yükümlülük mü doğurmuştur? Ki böylece hem toplumsal tepkiyi azaltmak hem de "uygarlık yolunda ilerlemek" mümkün olabilecektir. Ya da, tüm bu araçsal yanitlardan farklı olarak, bireyin toplumun diğer üyeleri ile etkileşim içinde kendi potansiyelini fark etmesi ve yaşama geçirmesi anlamında kendini gerçekleştirmesini sağlayabilmek için önemli bir koşulun, sağlıklı olmanın sağlanması mı amaçlanmalıdır? Halk Sağlığı disiplininin neden toplum sağlığını korumayı ve geliştirmeyi amaçlaması gerektiği biçimindeki etik sorusuna verilecek yanıt, açıktır ki, disiplinin ahlaki yükümlülüklerinin nasıl tanımlandığını, dolayısıyla da Halk Sağlığı uygulamalarının Turk J Public Health 2015;13(2) kapsamını, savunulan - itiraz edilen politikaları, çalışma alanlarını, araștırma sorularını, geliştirilecek önerileri, özetle disiplinin tüm üretimini / üretmediğini belirleyecektir.

$\mathrm{Bu}$ yazıda, yukarıda tanımlanan sorudan hareket ederek öncelikle temel kavramlardan söz edilmekte, sonrasında, Halk Sağlığı disiplininin ahlaki kurallarına dayanak olan etik değerleri ve ilkeleri temellendirilmektedir.

\section{Tanımlar}

Ahlak; belli bir toplum, kültür, zaman, yer, çalışma alanı, hatta kişi için geçerli olan, diğer deyişle tanımlamaları bunlara göre değișen değersel / normatif kurallar iken, Etik, kısaca "ahlak'ın felsefesi" olarak tanımlanabilir. Epistemoloji, Ontoloji ve Estetik ile birlikte felsefenin dört temel alanından birini oluşturan Etik; değerlerin ve kuralların ne'liği (non-normatif etik), ahlaki kuralların/normların ne olması gerektiği (normatif etik) ve Etik'in nasıl yapılması/çalışılması gerektiği (metaetik) üzerinedir. Etik'in çalışma alanları içinde; Meslek Etiği, İş Etiği, İletişim Etiği, Medya Etiği, Çevre Etiği gibi pek çok alan bulunmaktadır. Bunlardan Meslek Etiği alanı içinde tıbbi uygulamalardan kaynaklanan değer sorunlarını inceleyen Tıp Etiği alanı yer alır. Deontoloji (Deontos - Logos) ise, 'görev bilgisi / öğretisi' anlamında, belli bir mesleği uygularken uyulması gereken ahlak kuralları olarak tanımlanabilir. Kısaca Etik Ahlak'ın felsefesi, Ahlak belli değerleri korumayı amaçlayan kurallar iken Deontoloji belli bir alandaki ahlak kurallarıdır. $\mathrm{Bu}$ tanımlamalarda sıkça yapılan bir hata, Etik kavramını Ahlak'a eşitleyerek kullanmaktır; oysa tanımlamalar dikkate alındığında bir eylemin Etik'e değil ancak Ahlak'a aykırı ya da uygun olabileceği görülecektir. Bir başka hata, Etik Kurulu yapılanmasını Onur Kurulu ile eşanlamlı kullanmaktır. Etik Kurulu'nun işlevi, Etik'in tanımı ile bağlantılı olarak, belli bir değer sorununda haklı çıkarılabilecek eylemi seçmek ya da yaratmak üzere gerekçeli görüş oluşturmak iken, çeşitli adlandırmaları ile Onur Kurulu, Haysiyet 
Divanı, Disiplin Komitesi ya da Ahlak Komitesi, belli bir eylemin benimsenmiş ahlaki kurallara uygunluğunu değerlendirmekle görevlidir. Etik Kurulu oylama yapmak, oybirliğiyle karar almak durumunda değildir; karar değil, görüş oluşturur. Gerekçelerini belirtmek koşuluyla birden fazla görüş oluşturabilir, görüşleri danışmanlık verdiği kurum için bağlayıcı değildir. Onur Kurulu ise aksine, karar alır, kararlarını meslek ahlakı kurallarına dayandırır ve kararları bağlayıcıdır. Etik Kurulu'ndan farklı olarak, kararları ilgili düzenlemelerde yer alan yaptırımların uygulanmasını içerebilir; çünkü işlevi disipline etmektir. Elbette bir mesleğin ahlaki disiplininin nasıl sağlanabileceği ya da Onur Kurulu'nun etkin olup olamayacağ ayrı tartışma konularıdır; ancak sözü edilen ayrımları gözetmeden tartışmanın üretici olmayacağı açıktır.

Alanların sınırlarının çoğu kez birbirleriyle geçişli olduğu ve bu tür sinıflama girişimlerinin temelde düşünme süreçlerine bir yöntem sağlamayı hedeflediği göz önünde tutularak, sayılan çalışma alanlarının yanına, Biyoetik de eklenebilir. Özellikle ABD kaynaklı metinlerde 'Tıp Etiği' ile eşanlamlı kullanılabilse de, 'Biyoetik' sözcüğü daha geniş kapsamlı olarak, "Biyolojik disiplinlerin uygulamalarından kaynaklanan etik sorunlarıla ilgili çalışmalar" biçiminde anlaşılmalıdır: ${ }^{1}$

"Tıp Etiği Biyoetik'in ana bileşenlerinden biri olsa da, Biyoetik Tıp Etiği'nden daha geniş bir alana yayllır ve çevre bilimleri, cinsellik, üreme, genetik, nüfus, işsizlik, yoksulluk, ayrımcilık, suç, savaş ve işkence gibi insanların sağlı̆̆ını olumsuz etkileyen çeşitli sosyopolitik ahlaki konuları da kapsar."

Doğrudan insan ve toplum sağlı̆̆ıyla ilgili olan yukarıdaki tanımlama, Halk Sağlığı disiplininin çalışma alanlarıyla birlikte düşünüldügünde, her iki disiplinin çalışma alanlarının birbirlerine paralel olduğu saptamasında bulunulabilir. Benzerlik, Halk Sağlığı çalışma alanları dikkate alındığında da görülmektedir: "Sağlık ekonomisi", "Demografi”, "Sağlık eğitimi”, "Çevre sağlığı”,

Turk J Public Health 2015;13(2)
"Toplum beslenmesi", "Bulaşıcı hastalıklar", "Üreme sağlığı", "Kronik hastalıklar ve engellilik", "İş sağlığı" gibi. Bu noktada, kesişen bir küme olarak, Halk Sağlığı Etiği alanının tanımından söz etmek uygun olacaktır. Halk Sağlığı Etiği, özet ifadeyle, Halk Sağlığı uygulamalarından kaynaklanan değer sorunlarıyla ilgilenir. Zorunlu bağışıklamadan toplum sağlığını geliştirme programlarına dek pek çok Halk Sağlığ uygulaması çeşitli değer sorunlarının ortaya çıkmasına neden olabilmekte, sağllk çalışanları ve Halk Sağlığı uzmanları "Tütün kullanımını azaltmayı ya da günlük bedensel aktiviteyi artırmayı hedefleyen politikaların bireyin özerk kararlarını çiğnemesi haklı çıkarılabilir mi?", "Bireyin sağlık davranışları sağlık hizmetine erișim hakkını kullanabilmesinin koşulu olarak tanımlanmalı mı?", "Bulaşıcı hastalıklarda hizmet sunma yükümlülüğü için haklı çıkarılabilen bir sınır var mıdır?" gibi pek çok soruyla karşı karșıya kalabilmektedir. Bu bir Etik alanı olduğundan, henüz yaygın uzlașı sağlanmış ahlaki kurallar oluşturulamamıştır; dile getirilen farklı görüşler etik sorunlarının oluşumu ya da çözümüne yönelik olarak yeterince yol gösterici olmaktan henüz uzaktır.

Etik, Ahlak, Deontoloji, Biyoetik, Tıp Etiği ve Halk Sağlığı Etiği alanlarının tanımlamalarından sonra, son olarak, Halk Sağlığı disiplinini tanımlamak uygun olacaktır. Çünkü Halk Sağlığı Etiği'nin sorduğu sorular ve yanitları ile meslek ahlakı yükümlülüklerinin neler olacağı, disiplinin tanımına ilişkin çizilecek çerçeveye göre değişkenlik gösterecektir.

Halk Sağlığı uygulamalarının ilk örnekleri, bulaşıcı hastalıkların yayılımını engelleme ve onlardan korunma önlemlerinin sistemli biçimde uygulanması ile ortaya çıkmıştır. Ancak bu tür uygulamaların da etkisiyle, J. Williams'ın “Tıp Etiği Elkitabı"nda vurguladığı gibi “20. yüzyılda Halk Sağlı̆̆ı ve diğer sağlık hizmetlerinin ('özel' ya da 'bireysel') şanssiz biçimde ayrılmasına tanıklık edilmiştir." $2 \mathrm{Bu}$ şekilde ortaya çıkan anlayış Halk Sağlığı'nı uzmanlık dallarından biri olarak görmekte, toplum sağlığıyla sadece Halk Sağlığı disiplininin ilgilenmesi gerektiğini, Halk 
Sağlığı'nın ise sadece koruyucu önlemlere odaklanan bir disiplin olduğunu düşünmektedir. $\mathrm{Bu}$ anlayıș, günümüzün piyasa temelli politikalarının gereksinim duyduğu Halk Sağlığı yaklaşımını da tanımlamış olmaktadır: Merkezi ya da yerel yönetimlerce sunulacak sınırlı kapsamdaki koruyucu sağlı hizmetleriyle ilgilenen, fakat burada da bireye yönelik ve daha çok teknik önlemler üzerine yoğunlaşan, bütünlüklü bakmayan, toplum sağlı̆̆ sorunlarının kökenlerindeki belirleyenleri dikkate almayan bir yaklaşım.

Buna karșın 'Halk Sağlığı'; bir uzmanlık alanının, bir disiplinin adı olmasının yanı sıra, daha geniş kapsamlı olarak "toplum hekimliği" anlamında, sağlığa bütüncül yaklaşan, sağlık hizmetinin sadece sağaltıcı değil, koruyucu, geliştirici ve esenlendirici bileșenlerinin de olduğunu, sağlık hizmetlerinin kamu tarafından finanse edilmesi, nüfus temelinde örgütlenmesi, ekip hizmetiyle, toplum katılımıyla ve gereksinime göre sunulmasını savunan tıp anlayıșının adıdır.

\section{Ahlaki yükümlülüklerin temel aldığı değerler}

$\begin{array}{ccc}\begin{array}{c}\text { Temel } \\ \text { içeriklerini }\end{array} & \begin{array}{c}\text { kavramların } \\ \text { yukarıdaki }\end{array} & \begin{array}{c}\text { anlam } \\ \text { biçimde }\end{array}\end{array}$
tanımladıktan sonra, yazının bu bölümünde, 'toplum hekimliği' anlamındaki Halk Sağlı̆̆ı'nın temel aldığı etik değerlerinden söz edilecek, böylece bu değerlerden kaynaklanan meslek ahlakı kurallarının tanımlanması için bir temel sağlanacaktır.

Normatif etik alanında ahlak kuralları ahlak ilkelerine, ilkeler değerlere ve nihayet değerler ise kurama ('bilimsel kuram' değil, 'felsefi yaklașım' anlamında) dayandırılarak gerekçelendirilir. Neden o değerlerin sahiplenildiğini ve kuralların oluşturulduğunu açıklayan kuramdır; kuram aşamasındaki zayıflıklar silsile halinde tüm düşünce sistematiğini ve argümanların ikna ediciliğini etkileyecektir. Ancak kısalık adına, bu yazıda değerler ve onlara temellenen ilkeler ile yetinilecek, onların dayandığı kuramdan söz edilmeyecektir.
Halk Sağlı̆̆ı yaklaşımının temel aldığı değerler, yazının girişinde sorulan "Halk Sağlığı'nın neden toplum sağlığını korumayı ve geliştirmeyi amaçladığı”, daha doğru deyişle "bunu amaçlayan bir disiplinin neden var olduğu" sorusuna verilen yanittan kök alır: Bireyin kendisini gerçekleştirmesi. $\mathrm{Bu}$ soruya verilen diğer yanitların neden araçsal olduğu ve sahiplenmemek için nasıl özen gösterilmesi gerektiği ayrıca ayrıntılı olarak tartışılmalı. Kendini gerçekleştirme kavramını daha sağlam ifade etmek için Maslow'un gereksinimler piramidinin en üst düzeyi mi, yoksa örneğin eşitsizliklerin ve sömürünün olmadığı bir toplumda bireylerin potansiyellerini birlikte keşfetmeleri, kullanmaları, artırmaları düşüncesi mi kılavuz alınmalı; yine ayrıca ayrıntılı ifade edilmeli. Örneğin bireyler tek başlarına Maslow'un piramidinde en üste çıkabilmenin önündeki toplumsal, ekonomik, politik ve kültürel engelleri aşabilir mi? Tüm olumsuz koşullara rağmen kendisini gerçekleștirmiș sıra dıșı insanlar, sanatçlar, bilim insanları, sporcuların var olması bu modeli yeterince sağlam kılar mı? Önemli olan olağanüstü yeteneklerin şans, irade ve tutkuyla birleştiğinde piramidin en üstüne çıkabilmesi midir, yoksa şansı olabildiğince kontrol ederek tüm insanların kendi potansiyellerini olanaklardan hakkaniyetli yararlanarak yaşama geçirmesi midir? $\mathrm{Bu}$ yazı özelinde ikinci görüş benimsenerek ilerlenmekte, neden bu görüşün benimsenmesi gerektiği gerekçelendirilmemektedir.

Kendini gerçekleştirmek, ancak; a) temel gereksinimlerin sağlanması ve böylece gereksinimleri karşılama kaygısının / kavgasının yaşamın temel amacına dönüșmesinin önlenmesi, b) bireyleri birlikte öğrenmeye, keşfetmeye, gelişmeye teşvik edecek ortamın / olanakların yaratılması ve c) engellerin olabildiğince ortadan kaldırılması ile olanaklı ise, tüm bunları sağlamak için dıș dünyayı bilmek, böylece kontrol altına almak ve amaçlar doğrultusunda değiștirebilmek önkoşuldur. Maddi gerçekliği, onun bileșenlerini, belirleyenlerini, dinamiklerini ve etkileşimlerini bilmek bu derece yaşamsal ise, doğal olarak gerçeklik bilgisini görece 
en güvenilir biçimde veren aracın, bugünün bilimsel yönteminin kullanılması gerekecektir. Öyleyse, kendini gerçekleștirme'yi kök almak, bilimsel yöntem kullanmaya ve onun ürettiği bilgiyi temel almaya büyük bir değer atfedilmesini gerektirir.

Yanı sıra, temel gereksinimlerin bir alt bileşeni olarak, sağlık hakkı kapsamında sayılan koşulların karşılanması gerekir. Sağlık hakkı, her bireyin sadece gereksindiği sağlık hizmetlerine değil, sağlığın tüm belirleyenlerine ilişkin en iyi olanaklara kavușma hakkını ifade etmektedir: ${ }^{3}$

"Herkesin, kendisinin ve ailesinin sağlığı ve refahı için yeterli yaşam standartlarına sahip olmaya hakkı vardır. Bu hak; beslenme, giyim, konut, sağlık hizmetleri ile gerekli toplumsal hizmetleri ve isssizlik, hastalık, sakatlık, dulluk, yaşlılık ya da kendi denetiminin dışındaki koșullardan kaynaklanan geçimini sağlayamama durumlarında güvenlik hakkını kapsar."

Son olarak, engellerin olabildiğince ortadan kaldırılması koşulu; eşitsizliklerle ve sömürüyle mücadeleyi, insanlık yararının öncelenmesini ve kaynakların gereksinime göre dağıtılmasını zorunlu kılan bir adalet anlayışını zorunlu kılar.

\section{Değerlerin doğurduğu ilkeler}

Yazının yukarıdaki bölümlerinde temel kavramların tanımlarından söz edilmiş, sonrasında Halk Sağlığı disiplininin değerleri temellendirilmiștir. Bu değerlerin hangi ilkeleri doğurduğu yazının bu bölümünde ele alınacaktır.

Halk Sağlığı uygulamaları için ilk planda, "toplum sağlığı sorunlarını öncelemek", "kaynakları adil dağıtmak", "toplumu bilgilendirmek / eğitmek" ve "çılkar çatışmalarından kaçınmak" gibi yükümlülükler akla gelebilir. Öyle ki, bu yükümlülüklerin Halk Sağlı̆̆ı'nı teknik bir disipline sinırlayan anlayışça da, aksine, sağlığa bütüncül yaklaşan anlayışça da sahiplenileceği, bu yükümlülüklerin tüm yaklaşımlar için ortak bir payda oluşturacağı ileri sürülebilir. Bununla birlikte, yükümlülüklerin yaşama nasıl geçirileceği, yukarıda sözü edilen değerlerin korunup korunmamasıyla doğrudan ilişkili olacaktır. Halk Sağlığı'nı piyasanın gereksinimleri kapsamında teknik bir disipline hapsetmeye çalışan yaklaşımın ona biçtiği işlev, bir üst-yapı olarak benimseyeceği ahlaki yükümlülükleri, işini düzgün yapmak, dürüst davranmak gibi bireysel erdemlere sınırlayacak, sağlığın toplumsal belirleyenlerini görmezden gelip yaşam biçimi eğitimi / değişimini vaaz etmek normlaşacaktır. Halk Sağlığı'nı 'toplum hekimliği' anlamında tanımlayan yaklaşımın belirleyeceği ahlaki yükümlülükler ise açıtır ki farklı olacak, kendini gerçekleştirme ve onunla bağlantılı değerlerin korunması doğal olarak bașka ilkeler doğuracaktır. Gerekçelerin sağlamlığı üzerinden uzlaşıyı kolaylaştırmak adına, bu türden, Halk Sağlığı için 'olmazsa olmaz' ilkeler aşağıda argüman biçiminde ifade edilmiștir.

- Halk Sağlığı yaklaşımı sağlığın tüm belirleyenlerini dikkate alır.

Değerli tutumun bilimsel bilgiye saygı göstermek yönünde olduğundan hareketle, aşağıdaki gibi bir argüman kurulabilir:

Öncül.1 - Bilimsel bilgiyi dikkate almak, bilim insanları ve bilimsel bilgiyi kullanan modern tıbbın uygulayıcıları olan sağlık çalışanları için ahlaki bir yükümlülüktür.

Öncül.2 - Bilimsel bilgi; birey ve toplum sağlığının çok sayıda etmence belirlendiğini göstermektedir:

"Sağlık sorunları ile mücadele etmek için sağlık hizmetleri tek başına yeterli bir araç sağlayamaz. Bireylerin ve toplumların sağlık düzeyi; sadece erişebildikleri sağlık hizmetlerinin nitelik ve niceliği ile değil, fakat bundan daha çok barınma, beslenme, çalışma, çevre koşulları, eğitim düzeyi, toplumsal sınıf gibi dış / çevresel etmenlerce belirlenmektedir" 4

Sonuç - Toplum sağlığı sorunlarına ilişskin yürütülecek araştırmalarda, uygulamalarda, 
olgulara ilişkin saptama, çözümleme ve önerilerde sağlığın tüm belirleyenlerini ("nedenlerin nedenlerini") dikkate almak gerekir.

Örneğin Sağlıkta Dönüşüm ile getirilen performansa dayalı ödeme, kârlılık, maliyetetkinlik gibi politikaların, suların ticarileştirilmesinin, termik santralların, ilaçta patent yasalarının, ulusal ve uluslararası ekonomi, tarım, gıda, barınma, enerji, ulaşım ve iletişim politikalarının, insan hakları ihlallerinin, savaşların, özetle toplum sağlığını belirleyen nedensellik ağındaki tüm etmenlerin sağlığ etkilediğine dair bilimsel bilgi, Halk Sağlığı'nın çözümleme ve önerilerinde dikkate alınmalıdır. Aksi, bilimsel bir yaklaşım olmayacak, Halk Sağlığı disiplininin var oluş amacına değil, tersine hizmet edecektir.

- Halk Sağlığı yaklaşımı, sağlığın tüm belirleyenlerine ilişkin en iyi koşullara kavuşma savunusunu içerir.

Sağlığın çoklu belirlenimine ilişkin bilimsel bilgi, disiplinin var oluş amacı / iddiası ve sağlı hakkı ile birlikte düşünüldüğünde, Halk Sağlı̆̆ı yaklaşımının sağlık hakkı savunusunu içermesini gerekli kılmaktadır:

Öncül.1 - Halk Sağlığı disiplininin varlık nedeni, birey ve toplum sağlığını korumaya ve geliștirmeye yönelik bilgi üretmek ve girişimde bulunmaktır.

Öncül.2 - Bilimsel bilgi; birey ve toplum sağlı̆̆ının çok sayıda etmence belirlendiğini göstermektedir.

Öncül.3 - Bireyin kendisini gerçekleştirebilmesi için önkoşullardan biri, sağlık hakkı çerçevesinde tanımlanan tüm belirleyenlere iliş̧in en iyi koşullara kavuşmak / en iyi nitelikteki olanaklardan yararlanabilmektir.

Sonuç - Öyleyse Halk Sağlığı yaklaşımı; sağhığ belirleyen tüm koşulların iyileștirilmesi ve gerekli ise düzeltilmesi savunusunu içermelidir.
Gereksinilen sağlık hizmetine erişim hakkını da içeren bu savunu, kaçınılmaz olarak eşitsizliklere ve eşitsizlikleri üreten ya da müdahil olmayan politikalara itiraz etmeyi gerektirecektir. R. Virchow'un sözüyle "Tıp toplumsal bir bilimdir ve siyaset tıbbın büyük ölçekteki halinden başka bir şey değildir" ve bu anlamda Halk Sağlığ uygulamalarında "politik olmak"tan kaçınmak olanaklı değildir. Bu ilkenin Halk Sağlığı uzmanının kişisel değerleri, ideolojisi, politik düşünceleri ile ilgisi kurulamaz; ilke tümüyle Halk Sağlığı disiplininin varlık nedenine bağlıdır. Halk Sağlığı uzmanının kișisel değerleri farklı olabilir, kişi olarak örneğin yaşamının merkezine bilimsel bilgiyi değil inancı koyuyor, sağlık hakkına saygı duymuyor ya da şirket çıkarlarının bazı durumlarda öncelenmesi gerektiğini düşünüyor olabilir. Ancak Halk Sağlıkçı olarak mesleğini uygulayacaksa, tıpkı bir hekimin yapması gerektiği gibi, kişisel değerlerini mesleki etkinliklerinde dikkate alamaz. Mesleği hangi ahlaki yükümlülükleri doğurmuş ise onları koruyarak eylemek durumundadır. $\mathrm{Bu}$ nedenle Halk Sağlı̆̆ı uzmanı, kişisel ideolojisi ne olursa olsun, mesleğini uygularken sağlığı belirleyen tüm koşulların iyileştirilmesi ve gerekli ise düzeltilmesini savunusunu ilke olarak sahiplenmelidir.

- Halk Sağlığı yaklaşımı, devlet eliyle finanse edilen, örgütlenen ve sunulan sağlık hizmeti modelini savunur.

Öncül.1 - Sağlık hakkını dikkate alan sağlık hizmeti, gereksinim ölçütüne göre sunulmalıdır.

Öncül.2 - Sağllk hizmetlerinin gereksinim ölçütüne göre ve tüm bireylere adil biçimde sunulabilmesi için, hizmetin olanakl en etkin biçimde finanse edilmesi, örgütlenmesi ve sunulması gerekir.

Öncül.3 - Bilimsel bilgi ancak kamucu, sağlığa bütüncül yaklaşan hizmetin etkin olduğunu göstermektedir: 
"Sağlık hizmetleri ancak; kamu kaynaklarından finanse edilerek, nüfus temelli, ekip çalışmasıyla ve toplum katılımıyla yürütülen, gezici hizmetleri içeren bir örgütlenmeyle, geliștirici, koruyucu, sağaltıcl ve esenlendirici boyutlarıyla bir bütün olarak sunulduğunda sağllk gereksinimlerini karşllayabilmektedir" ${ }^{\prime 5}$

Sonuç - Öyleyse Halk Sağlığı yaklaşımı devlet eliyle finanse edilen, örgütlenen ve sunulan sağlık hizmeti modelini savunmalıdır.

- Halk Sağlığı yaklaşımı; disiplini değersel ve bilimsel temellerinden uzaklaştıran, teknik bir alana sıkıștıran anlayışa karşı çıkar.

Öncül.1 - Devletin küçültülmesi / kamusal hizmetlerin piyasalaştırılmasına yönelik politikalar sağlık hizmetlerini devletin bir yükümlülüğü değil, bir piyasa nesnesi olarak tanımlamaktadır.

Öncül.2 - Piyasanın dinamikleri öncelendiğinde, sağlık sorunlarının belirleyenlerine / temel nedenlerine değil, sonuçlara, diğer deyişle hastalık tedavisine odaklanılmaktadır.

Öncül.3 - Piyasanın dinamikleri öncelendiğinde, ekonomik maliyet ve getiri hesabı kaçınılmaz olarak temel ölçüt olmakta, sunulacak sağlık hizmetinin nitelik ve niceliği gereksinim olup olmamasına göre değil, maliyet-etkin olup olmamasına göre belirlenmektedir.

Öncül.4 - Koruyucu ve geliștirici hizmetler ancak işgücünün sürekliliğini sağlayabildiği ölçüde maliyet-etkin olabilmektedir. Bu nedenle piyasanın gereksinim duyduğu Halk Sağlığı yaklaşımı, özgül olaylara müdahil olan bir tür uzman teknisyenliğe, suların klorlanması, salgınların soruşturulması gibi görece teknik alanlara daralmakta, toplum sağlığı sorunlarının kökenindeki belirleyenler bu yaklaşımın görme alanı dışında kalmaktadır.

Öncül.5 - a) Toplum sağlı̆g sorunlarının ve eşitsizliklerin kökenindeki belirleyenleri dikkate almamak Halk Sağlı̆̆ı yaklaşımını etkisizleştirmektedir.

b) Halk Sağlı̆̆ı yaklaşımının sağlık politikalarında ve sağlık hizmetlerinde etkisiz / geçersiz kılınması, yaşam ve sağlığın önlenebilecek sorunlar nedeniyle yitirilmesine neden olur. Bu durum yaşam ve sağlık haklarını ihlal eder.

Sonuç - Halk Sağlığı yaklaşımını deforme eden, bilimsel temelinden uzaklaștıran ve sağlık hakkını ihlal eden politikalara karşı çıkılmalıdır.

Argümanlar ileri sürdükleri savların dayandığı gerekçeler (öncüller) dikkate alınarak analiz edilir. Bir argümanın dayandığı bilgisel öncül yanlış ise ya da değersel öncülü korunması gereken bir değeri korumuyor ise argüman sağlam değildir. Tersinden, eğer bilgisel öncülleri doğru, değersel öncülleri korunması gereken değerleri koruyorsa, bu durumda o argümana itiraz etmek için ya gerçekliği görmezden gelmek ya da söz konusu değere saygl göstermiyor olmak gerekir. Örneğin "Sağlık hizmetleri piyasa kurallarına tabi kılındığında maliyet-etkinlik öncelikli ölçüt olur" öncülü bilgiseldir ve doğruluğu araştırmalarla gösterilmiştir. "Sağllk hakkl gereğince sağllk hizmetleri ödeme gücüne göre değil, gereksinime göre sunulmalıdır" öncülü değerseldir ve sağlık hakkının bir değer olarak evrensel kabul edilmişliğine dayanır. Bu iki öncülün sonucu olan "Öyleyse sağlık hizmetleri piyasa kurallarına göre sunulması sağlık hakkına aykırıdır" savı, hem iç-tutarlı, hem de sağlamdır. Bu argümana iç-tutarlığı koruyarak itiraz edebilmek için; ya piyasa temelli yaklaşımlar için maliyetetkinliğin temel ölçüt olduğuna itiraz etmek gerekir, ya da sağlık hakkına saygı duyulmadığı, sağlık hakkının benimsenmediği, bireylerin sağlık hakkının olmadığı düşüncesi benimseniyor olmalıdır. Halk Sağlıkçının mesleğini uygularken bilimsel bilgiye ve sağlı hakkına saygı duyma yükümlülüğü bulunduğundan yukarıdaki argümanlarla ifade edilen ilkeleri kabul etmesi gerekecektir. Bu ilkeleri kabul 
edip içselleștirmeden, hızla akla geldiği gibi ezbere sözlerle ya da altını doldurmadan ifade edilen "kaynaklar adil dağıtılmalı" ya da "toplum sağlı̆̆ı sorunları öncelenmeli" gibi ödevleri anlamlı bir zemine oturtmak olanaklı olmamakta, bu ifadelerin neredeyse birbiriyle açıkça çelişen pratiklere karşılık gelmesine yol açlabilmektedir.

\section{Sonuç}

$\mathrm{Bu}$ yazıda, meslek ahlakı kuralları için dayanak oluşturmak üzere, Halk Sağlığı disiplinin temel değer ve ilkeleri temellendirilmiştir. Bireyin toplumun diğer bireyleriyle etkileşim içinde kendisini gerçekleștirmesine sağlık alanından katkıda bulunmak üzere; bilimsel yöntem ve bilginin kılavuzluğu, sağlık hakkı, insanlık yararı ve eşitsizliklere karşı çıkan, kaynakların gereksinime göre dağıtılmasını savunan bir adalet anlayıșı, disiplinin temel değerler kümesini olușturmaktadır. $\mathrm{Bu}$ değerler; sağlığın tüm belirleyenlerini uygulamalarda, araştırma, çözümleme ve önerilerde dikkate almak, sağlığı olumsuz etkileyen her türlü etmene karşı müdahil olmak ve bilimsel doğruları savunmak, toplumdan yana Halk Sağlığı yaklaşımının piyasalaştırma sürecinde tıp tarihinden, insanlık kazanımları arasından silinmesine karşı çıkmak gibi ilkeleri sahiplenmeyi gerektirmektedir.

Bu anlamıyla Halk Sağlığı yaklaşımı, özünde, sözü edilen değerlere dayanan ahlaki bir pozisyondur, bir adalet talebidir. Tüm uğraşları, savunuları ve itirazlarının temelinde bu değerleri koruma kaygısı yatar. Aynı nedenlerle Halk Sağlı̆̆ yaklaşımı, sadece Halk Sağlığı uzmanlarının değil, tüm sağlık çalışanlarının benimsemesi ve savunması gereken bir yaklaşımdır. Halk Sağlığı, olması gereken Tıp'tır.

Şimdi önümüzde, geniş uzlaşıyı sağlayacak bir yöntem ile, sayılan değer ve ilkelere dayanan ahlaki kuralları tanımlamak görevi bulunmaktadır. İçerikleri tümüyle tartışmaya açık olsa da dünyada pek çok örneği bulunan bu tür kuralları tanımlamak, ülkemiz için önemli bir gereksinimdir. Böylesi kurallar, bir tıp dalı değil tıbbın kendisi olan Halk Sağlı̆̆ disiplininin, varlık iddiasıyla tutarlı biçimde toplum yararını önceleyerek üretmesinin güvence altına alınması yönünde bir adım olmanın yanı sıra, aynı zamanda, gerek eğitim gerekse de bilgi ve politika üretimi çalışmalarında yol gösterici olacaktır. Özgürlüğü değil deyim yerindeyse başıboşluğu önlemek, çalışmaları yönlendirmek ve etkinlikleri değerlendirmek kolaylaşacak, alanın saygınlığı artacaktır. Belki de en önemlisi, meslek ahlakı kurallarının tanımlanması; bugün piyasanın Halk Sağlığı üzerindeki açık ve giderek yoğunlaşan 'onaylayıverme' baskısına karşı koymayı kolaylaştıracak, kişisel çıkarları ya da şirket çıkarlarını toplum yararının önüne geçirmenin meslek ahlakına aykırı olduğu tüm Halk Sağlıkçılarca tartışmasız kabul edilecektir. $\mathrm{Bu}$ yazının, böylesi bir sürece katkıda bulunmasını umuyorum.

Bilgilendirme:

Bu yazl, 2-6 Ekim 2012 tarihleri arasında Bursa'da düzenlenen 15. Ulusal Halk Sağlığı Kongresi'nde yazarca sunulan "Halk Sağlığı alanında ahlak ve etik sorunları" isimli sözlü bildirinin geliştirilmesiyle oluşturulmuştur.

\section{Kaynaklar}

1. Gillon G. Bioethics, overview. İçinde: Chadwick R, ed. Encyclopedia of Applied Ethics. 1st ed. San Diego: Academic Press; 1998. s.306.

2. Williams J. Tıp Etiği Elkitabı. Ankara: Türk Tabipleri Birliği; 2006.

3. United Nations, The Universal Declaration of Human Rights. http://www.un.org/en/documents/udhr / (Erişim tarihi: 22 Haziran 2015)

4. Hart N. The social and economic environment and human health. İçinde: Oxford Textbook of Public Health. Detels R, Holland WW, McEwen J, Omenn GS eds. Oxford: Oxford University Press; 1997.

5. Fișek N.H. Halk Sağlığı'na Giriş. Hacettepe Üniversitesi: Ankara; 1983. 